\title{
Lactose Intolerance
}

National Cancer Institute

\section{Source}

National Cancer Institute. Lactose Intolerance. NCI Thesaurus. Code C3154.

Inability to fully digest and absorb lactose due to limited or no lactase activity in the small intestine. Congenital intolerance is inherited following an autosomal recessive pattern but is rare. It is more often due to a gradual decline of lactase production in adulthood following the ingestion of fewer lactose-containing foods or secondary to an intestinal mucosal brush-border injury. Prevalence is highest among Asians, Native Americans and Africans. Clinical signs include abdominal cramping, bloating, flatulence and diarrhea following the dietary intake of lactose. 